Di Prampero, P. E., Pendergast, D. R., Wilson, D. W. and Rennie, D. W., 1974 "Energetics of swimming in man". J.Appl.Physiol. 37 (1): 1-5.

Kemper, H. C. G., Verschuur, R., Clarys, J. P., Jiskoot, J. and Rijken, H., 1976 "Efficiency in swimming the front crawl". In: Biomechanics VB, edited by P. V. Komi. Baltimore: University Park Press, 243-249.

Treffene, R. J., 1978 "Predict performance by heart rate measurements". International Swimmer, January, 15-16.

\section{SOME CONCOMITANTS AFFECTING THE SKILL ADAPTATION OF NON-SWIMMERS DURING A TWELVE-SESSION TRAINING PROGRAMME}

\section{J. Atha* , A. D. Kinnear and J. S. Sawbridge \\ *Dept. of Human Sciences, University of Technology, Loughborough}

An adaptive process is undergone by the non-swimmer who learns to swim. Some influences affecting this process were surveyed in an extensive field experiment completed in 1967 but not published at the time, when 7353 non-swimmers from schools throughout England and Wales were taught to swim under one of the four treatment combinations of two methods of teaching, i.e. single-stroke and multi-stroke methods, and two administrative arrangements i.e. block (daily) and standard (weekly) lesson schedules. Also studied were the effects of selected supplementary techniques, e.g. flotation aids, flipper-float practices and land-drills, the importance of certain facilities, and some attributes of successful pupils and teachers. Success was measured each lesson by width and length tests, and at the end of the experiment by a five minute test.

Results confirmed that a few exceptional teachers obtain outstanding success rates. In general, however, achievements in the 12 sessions were modest. Overall $57.4 \%$ of the non-swimmers learned to swim a width and $34.5 \%$ a length, while those who passed both tests averaged 75.2 metres in the five minute test. By comparison a control group of 458 non-swimmers who received no teaching achieved results on the same tests of $52.0 \%, 28.2 \%$ and 71.2 metres respectively. These results for the experimental and control groups are similarly related at all ages from 9 years to 12 years. Although statistically significant, the differences between the groups give no cause for enthusiasm. Rather do they raise two queries, one about the economics of providing teaching cover for non-swimmers, the other about the nature of the training given to those charged with providing that cover. A second result, not without bearing on this, reveals that whereas the experienced teachers achieve significantly better results than the inexperienced, the qualified teachers show no particular superiority over the unqualified.
It is concluded that daily lessons are slightly superior to weekly lessons if success is judged by a simple test, but modestly inferior if a more robust test is adopted, that the multi-stroke method is superior to the singlestroke method at all ages from 9 years to 12 years, that success rate is largely independent of sex, very much a function of age, moderately an inverse function of class size, only little related to academic stream and unrelated to type of secondary school. It is thus also concluded that administrative policies and teaching practices affecting the non-swimmer would benefit from review.

SOME HAEMATOLOGICAL FINDINGS IN COMPETITIVE SWIMMERS UNDERTAKING A "TAPER" TRAINING PROGRAMME

R. J. Ratcliffe* , P. L. T. Willan, M. Mahon and K. M. Bagnall**'

Dept. of Anatomy, University of Manchester

Present addresses:

*The Royal Infirmary, Manchester

* *University of Alberta, Canada

In the weeks immediately preceeding important competitions many athletes and swimmers prepare by undertaking "taper" training programmes involving initially long and strenuous training sessions which become progressively shorter and less arduous nearer the competititon date. Such programmes are generally believed to enhance the likelihood of achieving good or improved performances.

The present study was undertaken to investigate changes in basic haematological parameters in athletes during a "taper" programme. Two groups of competitive swimmers (7 males, 8 females) were examined during an intensive eight week taper training programme. The average distances swum (per subject per week) were decreased progressively from $80 \mathrm{~km}$ to $20 \mathrm{~km}$ in the week before the competition. Swimmers who missed training sessions were excluded from the study. Control groups (8 males, 8 females) undertook no strenuous organised physical training. Samples of venous blood were collected from the subjects employing a standardised procedure at regular weekly intervals. Samples were analysed using a Coulter S System and values were obtained for red cell count, haemoglobin concentration, haematocrit, mean corpuscular volume (MCV), mean corpuscular haemoglobin (MCH), mean corpuscular haemoglobin concentration (MCHC) and white cell count.

In both individuals and groups there were significant differences between values at the start and end of the taper programme for some parameters, including red cell count, haemoglobin concentration and haematocrit, whereas the cellular indices MCV, MCH and MCHC 
remained relatively constant. Wide variations in white cell count were observed during the study in both the swimmers and control groups. These results were discussed in relation to various factors, including physical training, which may alter the concentrations of cellular components in the peripheral blood, either through altering the plasma volume and/or by altering the total red cell population.

\section{TRANSIENT OXYGEN UPTAKE IN TRAINED CHILDREN AT THE ONSET OF MAXIMAL ARM AND LEG EXERCISE \\ N. Armstrong*, B. Davies** and J. Mulhall** \\ "Movement Science Laboratory, City of Liverpool College of Higher Education \\ * "Metabolic Profile Unit, University of Salford}

This study was designed to compare the $\mathrm{VO}_{2}$ - on response of a group of well-trained, young swimmers at the onset of maximal arm and maximal leg exercise.

The cycling $\mathrm{VO}_{2}$ max and arm cranking $\mathrm{VO}_{2} \max$ of 10 male swimmers (age $14.5 \pm 1.3 \mathrm{yr}$ ) were determined using incremental, continuous protocols on a Monark ergometer. On the day following each of these tests the exercise intensity at which the $\mathrm{VO}_{2}$ max had been elicited was applied without any warm-up and the subjects maintained this intensity, either arm cranking or cycling, for five minutes. In all tests respiratory gases passed via a low resistance valve into an on-line computerised gas analysis system and heart rates were recorded using a bipolar lead. $\mathrm{VO}_{2}$ and associated parameters were recorded every 30 seconds.

The mean $\mathrm{VO}_{2}$ maxs elicited in the incremental tests (cycling, $3.48 \pm 0.57 \mathrm{I} / \mathrm{min}$; cranking $2.40 \pm 0.38 \mathrm{l} / \mathrm{min}$ ) were not significantly different from those elicited in the corresponding 5 minute constant intensity test (cycling; $3.34 \pm 0.46 \mathrm{I} / \mathrm{min}$; cranking, $2.43 \pm 0.29 \mathrm{l} / \mathrm{min}$ ). The changes in $\mathrm{VO}_{2}$ during the first four half minute periods of the constant intensity leg exercise expressed as a percentage of the final $\mathrm{VO}_{2}$ were not significantly different from the corresponding arm exercise changes expressed in the same manner.

There is no study of arm exercise or of the specificity of $\mathrm{VO}_{2}$ - on response in children with which to compare these results directly but they do not support the finding in adults that trained muscles are characterised by a relatively faster rise of $\mathrm{VO}_{2}$ at the onset of exercise. The methodology used does not make it possible to express the increase of $\mathrm{VO}_{2}$ as the half-time directly but the percentage changes in $\mathrm{VO}_{2}$ in leg exercise are considerably lower than those reported elsewhere (Macek and Vavra, 1980) using similar methodol- ogy with pre-pubescent boys. Further studies utilising breath by breath analysis are necessary to elucidate the initial kinetics of metabolic transients during exercise with trained children.

\section{References}

Macek, M. and Vavra, J., 1980 "The adjustment of oxygen uptake at the onset of exericse: A comparison between pre-pubertal boys and young adults". Int.J. Sports Med. 1: 70-72.

\section{AEROBIC CAPACITY AND OXYGEN DEBT RELATED TO CANOE RACING PERFORMANCE}

G. E. Cooper

Dept. of Physical Education, University of Birmingham



G. E. Cooper

In a previous study using high speed film analysis it had been established that the action of paddling a kayak was essentially that of a 2nd order lever system (Cooper, 1974). The canoe ergometer, as illustrated, was consequently designed to replicate the technique of actually paddling the kayak and was validated using EMG.

To a sample of 15 paddlers, who were all members of the Regional "Centre of Excellence", a stepwise submaximal procedure was used to predict the $\max \mathrm{VO}_{2}$ on the bicycle and canoe ergometers.

Max $\mathrm{VO}_{2}$ cycling was found to be not related to $\max \mathrm{VO}_{2}$ canoeing or to canoe racing performance in the 1000 metre event. However, the relationship between $\max \mathrm{VO}_{2}$ canoeing and paddling performance is highly significant.

With a sample of 11 international competitors; a continuous-type test to exhaustion was used on the canoe ergometer. The aerobic capacity and excess oxygen consumption during the immediate 10 minute recovery period were measured directly.

The $\max \mathrm{VO}_{2}$ canoeing and oxygen debt were both 